\title{
An Assessment of Submersion as a Mechanical Control Technique of Pomacea maculata eggs in Southern Florida, USA
}

\author{
April S. Ostrom ${ }^{1, *}$, Thomas C. Chesnes ${ }^{2}$ \\ ${ }^{1}$ Palm Beach Atlantic University, West Palm Beach, FL, 33416 \\ ${ }^{2}$ Palm Beach Atlantic University, Department of Biology, West Palm Beach, FL, 33416 \\ *Corresponding Author: aostrom@sfwmd.gov
}

Copyright (C) 2014 Horizon Research Publishing All rights reserved.

\begin{abstract}
Pomacea maculata is a freshwater snail native to various regions of South America. In the 1990's invasive populations of $P$. maculata began to establish in Texas, Florida, and Georgia. These snails have a high fecundity rate and feed on macrophytes. Water bodies in southern Florida undergo frequent fluctuations in water levels; most are controlled by pumps, culverts, gates and levees. A proposed control method for these snails is the inundation of the egg clutches. This study compared the hatching success of unsubmerged egg clutches with the hatching success of partially submerged egg clutches, the growth rates of snails hatched in the treatments, and determined if snails hatched in submerged conditions are viable to a shell length that exceeds $25 \mathrm{~mm}$, a size typically capable of reproduction. Hatchling success was not significantly different amongst treatments; likewise, growth rates were similar despite inundation. Pomacea maculata egg clutches submerged at various times during their incubation can become detached from the vegetation and sink or float. Floating egg clutches can be transported through water control structures and canals, thus facilitating the spread to non-impacted areas. Manual methods for removal of egg clutches and adults may prove more effective in control efforts.
\end{abstract}

Keywords Pomacea maculata, Southern Florida, Exotic Species, Mechanical Control

\section{Introduction}

Four species of the Pomacea genus have been introduced to the continental United States [1]. These non-native Pomacea species have been identified as $P$. haustrum(titan apple snail), P.canaliculata(channeled apple snail), P.maculata (island apple snail), and $P$. diffusa(spike-topped apple snail)[1]. Pomaceasp. feed predominantly on macrophytes[2] and have been observed consuming snails, snail eggs, and other invertebrates [3]. They can be an intermediate host to vertebrate parasites such as cercariae, Echinostoma, and Angiostrongylus cantonensis[4]. All Pomacea sp. lay eggs above the water and one of the observed predators of these eggs are fire ants, Solenopsis invicta [5].Pomacea sp. has been observed active at water temperatures ranging from $8 \mathrm{C}^{\circ}$ to $35 \mathrm{C}^{\circ}$ [6]. Pomacea maculata (island apple snail) and $P$. canaliculata(channeled apple snail) are considered a threat to agriculture by damaging crops and to native wetland ecosystems in the United States[1]. Invasive populations of $P$. maculata were established in Texas by 1989 , in Florida by the mid to late 1990s, and in Georgia by 2005 and this species continues to spread rapidly [1]. These invasive snails are native to Argentina, Brazil [7], Bolivia, Uruguay and Paraguay [1]. Egg clutches are laid on emergent macrophytes, clutches dry out and snails develop within one to three weeks [8]. Females can lay more than one clutch a week and have an average of 2064 eggs per clutch [9]. The high fecundity of these snails allows for the potential to outcompete native $P$. paludosa and devastate macrophytes in Florida's wetlands. The control methods for the Pomacea sp. include biological control, pesticides and draining heavily infested areas[8].

Established populations of P.maculata have been observed within the impoundments located at Arthur R. Marshall Loxahatchee National Wildlife Refuge (Refuge), Boynton Beach, FL. A common control and management method used to eradicate P.maculata was to dislodge egg clutches from substrate, and allow clutches to fall in the water. However, minimal research has been done on the $P$. maculata and the effects of inundation on egg clutches. Understanding the hatching success during water stress will allow for improved management and control efforts. This study has 3 objectives: 1)to compare the hatching success of unsubmerged egg clutches with the hatching success of partially submerged egg clutches, 2) to compare the growth rates between snails hatched from partially submerged egg clutches and snails hatched from unsubmerged egg clutches, and 3) to determine if 
snails hatched in submerged conditions are viable to a shell length that exceeds $25 \mathrm{~mm}$, a size typically capable of reproduction. $P$. maculata egg clutches submerged at various times during their incubation can become detached from the vegetation and sink or float. Floating egg clutches can be transported through pumps, culverts and gates facilitating the invasion of non-impacted areas.

\section{Materials and Methods}

\subsection{Objective I: Hatching Success}

\subsubsection{Egg Hatching}

The study was conducted at the Arthur $\mathrm{R}$ Marshall Loxahatchee National Wildlife Refuge in Boynton Beach, Florida initiated in spring 2010. Sixty-six P. maculata egg clutches (clutches) were collected from a canal located outside of the Refuge, but within Water Conservation Area One. To protect the clutches during relocation the entire section of plant where the egg clutch was affixed was removed. Clutches were kept in 38 liter aquariums $(61.6 \times 31.8 \times 32.4 \mathrm{~cm})$ for two weeks. Aquaria were placed in an outdoor area with a clear plastic roof. The aquaria were filled with dechlorinated 15-20liters of municipal water. Approximately 7-10 liters of water were removed and replaced with municipal water dechlorinated by aging and aeration twice a week. Predators were excluded by a chain link fence that encloses the area as well as securing the screen tops of the aquariums with tape. Aquaria were exposed to ambient air temperatures averaging $29^{\circ} \mathrm{C}$ and an average $13 \mathrm{~h}$ photoperiod.

Three treatments were used: an unsubmerged control group, a partially submerged group, and a group where the eggs were allowed to float. Two replicate tanks were used for each treatment. The two control replicates each contained eleven clutch/vegetation assemblages affixed to the sides with waterproof tape. Tank position and treatment were randomized. The bases of the clutches were maintained 5 to $10 \mathrm{~cm}$ above the water surface. All detached and disassociated clutches were removed and discarded. The two partially submerged replicates each contained eleven half submerged clutch/vegetation affixed to the sides with waterproof tape. All detached and disassociated clutches were removed and discarded. The two floating replicates each contained eleven floating clutches detached from vegetation.

Aquaria were checked daily for hatchlings. Hatchlings were removed by nets and individually counted on plastic trays in a laboratory. On day seven and day fourteen all aquaria water was strained through a screen into five gallon buckets, hatchlings were removed and counted. Data were analyzed using a Mann-Whitney-Wilcoxon test using SPSS statistical software (version 19).

\subsection{Objectives II and III: Growth Rates and Survivorship}

One hundred Pomacea maculata egg clutches were collected from A.R.M. Loxahatchee National Wildlife Refuge, Boynton Beach, Florida. Clutches were obtained by cutting off the section of vegetation it was adhered to. The clutches along with the vegetation were placed on wax paper and transported in a plastic container. Clutches were transported within 1 hour to a greenhouse with a clear roof, ambient air temperatures and predator exclusion. Egg clutch treatments were performed in ten 38liter aquaria $(61.6 \times 31.8 \times 32.4 \mathrm{~cm})$ with screen tops. The aquaria water level remained within $8-12 \mathrm{~cm}$ deep with mechanical aeration added.

There were two treatments in this study: an unsubmerged control and a partially submerged experimental group. Each treatment had five replicate tanks in randomized order. The control replicates each contained ten clutch/vegetation assemblages affixed to the sides with waterproof tape. The bases of the clutches were maintained 5 to $10 \mathrm{~cm}$ above the water surface. All detached and disassociated clutches were removed and discarded daily. The five partially submerged replicates each contained ten $1 / 2$ to $3 / 4$ submerged clutch/vegetation assemblages affixed to the sides with waterproof tape. Cut cabbage leaves were fed to snails in excess and were renewed every time the water was changed. Aquaria were checked daily for hatchlings.

On day 24 after hatching, 100 hatchlings were randomly selected from the treatment groups for measurement. It was necessary to wait 24 days since it was found handling prior to then cause damage to the hatchlings. Subsequently, the snails were measured with digital calipers every 2 weeks and reared until shell length exceeded $30 \mathrm{~mm}$ (approximately 4 months). Measurements were taken in millimeters $(\mathrm{mm})$ of the operculum width, shell length, and shell height. Snails were measured to the nearest $0.1 \mathrm{~mm}$ [10]. At the end of the study snails were euthanized by freezing.

\section{Results}

\subsection{Objective I : Hatching Success}

Egg clutches in the unsubmerged control treatments had higher rates of hatchling success than both the partially submerged and floating egg treatments (Table 1). Approximately $77 \%$ of clutches produced hatchlings in the control experiments versus 63 and 59\% in the partially submerged and floating treatments, respectively. The average number of hatchlings per clutch was also greatest in the control treatments (Table 1). No statistically significant differences were determined (Mann-Whitney-Wilcoxon, $\mathrm{p}>0.05$ ).

Hatchling rates were highest in the control group on day 7 (Figure 1).In both the partially submerged and floating treatments, hatching rates were lower than the control, but both started earlier on day 4.Peaks in hatching also occurred on day 7 for the experimental treatment clutches.

\subsubsection{Growth Measurements}


Table 1. Hatchling statistics per tank and treatment

\begin{tabular}{|c|c|c|c|c|}
\hline Treatment ID & $\begin{array}{c}\text { Total number of } \\
\text { egg clutches } \\
\text { hatched }\end{array}$ & $\begin{array}{l}\text { Percent clutches } \\
\text { hatched }\end{array}$ & $\begin{array}{l}\text { Total number of } \\
\text { hatchlings }\end{array}$ & $\begin{array}{l}\text { Average number of } \\
\text { hatchlings per clutch }\end{array}$ \\
\hline Unsubmerged Control 1 & 10 & 90.9 & 12655 & 1266 \\
\hline Unsubmerged Control 2 & 7 & 63.6 & 4660 & 666 \\
\hline Partially Submerged 1 & 4 & 36.4 & 3391 & 848 \\
\hline Partially Submerged 2 & 10 & 90.9 & 9175 & 918 \\
\hline Floating 1 & 7 & 63.6 & 3478 & 497 \\
\hline Floating 2 & 6 & 54.5 & 4317 & 720 \\
\hline \multicolumn{5}{|l|}{ Total Per Treatment } \\
\hline Unsubmerged Control & 17 & 77.3 & 17315 & 1018.5 \\
\hline Partially Submerged & 14 & 63.6 & 12566 & 897.6 \\
\hline Floating & 13 & 59.1 & 7795 & 599.6 \\
\hline
\end{tabular}

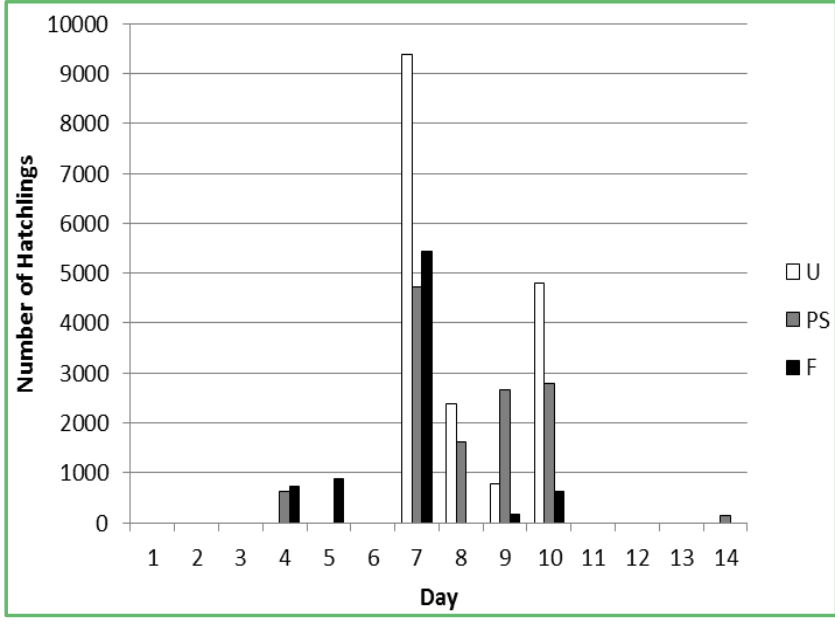

Figure 1. Hatchling numbers per day in eggs in the unsubmerged (U), partially submerged (PS) and floating (F) treatments.

\subsection{Objectives II and III: Growth Rates and Survivorship}

Growth rates for the three morphometrics measured show little difference between snails hatched from unsubmerged and partially submerged eggs. Measurements of average shell height (Figure 2) were similar through the measuring period; all snails reached a shell height of $30 \mathrm{~mm}$ within four months. Mean shell length (Figure 3) was also very similar between treatments, with variations between averages less than $1 \mathrm{~mm}$. Within three months, all snails exceeded a shell length of 25 $\mathrm{mm}$, and by the end of the experimental period (6 months), approximately $20 \%$ of the snails began to reproduce, producing eggs affixed on the side of the aquaria. Notably, the eggs clutches produced by those in the partially submerged treatment were larger than those hatched in the unsubmerged treatment. Measurements of operculum width are shown in Figure 4. As in the other measurements, growth rates were similar between snails in the two treatments. No statistically significant differences were observed between the daily measurements of any of the treatments, with the exception of the final operculum width measurements (Mann-Whitney-Wilcoxon, $\mathrm{p}=.02$ ).

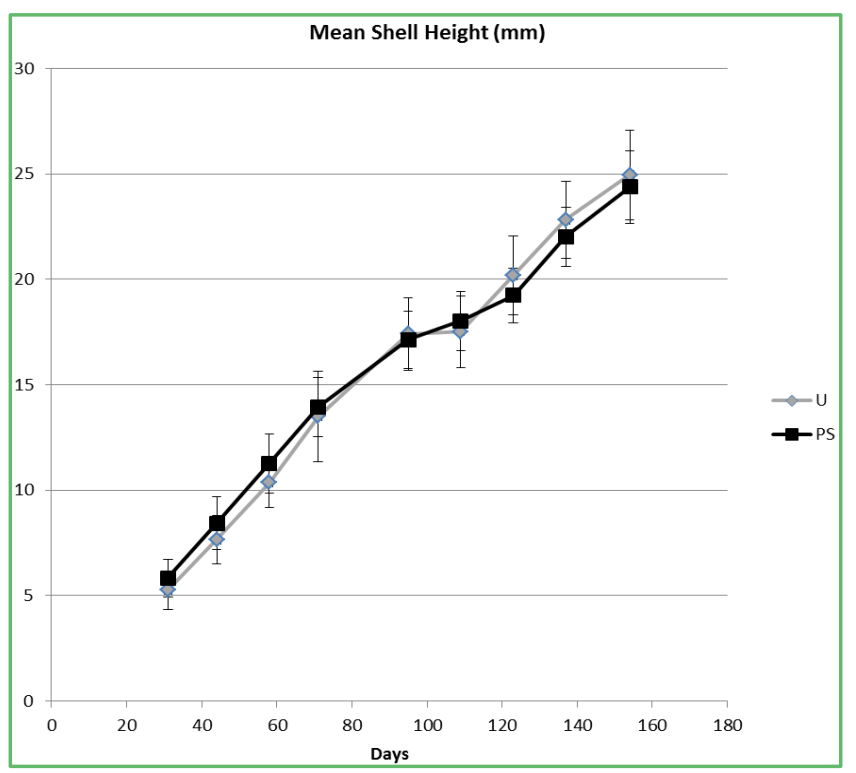

Figure 2. Growth rates in shell height between snails in the unsubmerged (U) and partially submerged (PS) treatments. Error bars represent standard deviation. 


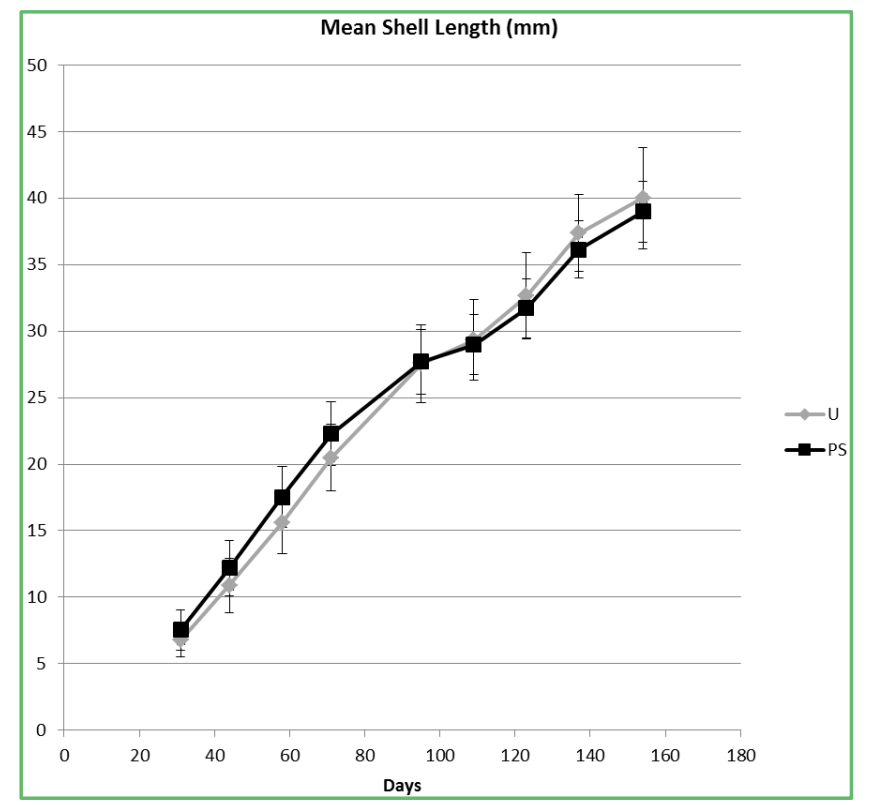

Figure 3. Growth rates in shell length between snails in the unsubmerged (U) and partially submerged (PS) treatments. Error bars represent standard deviation.

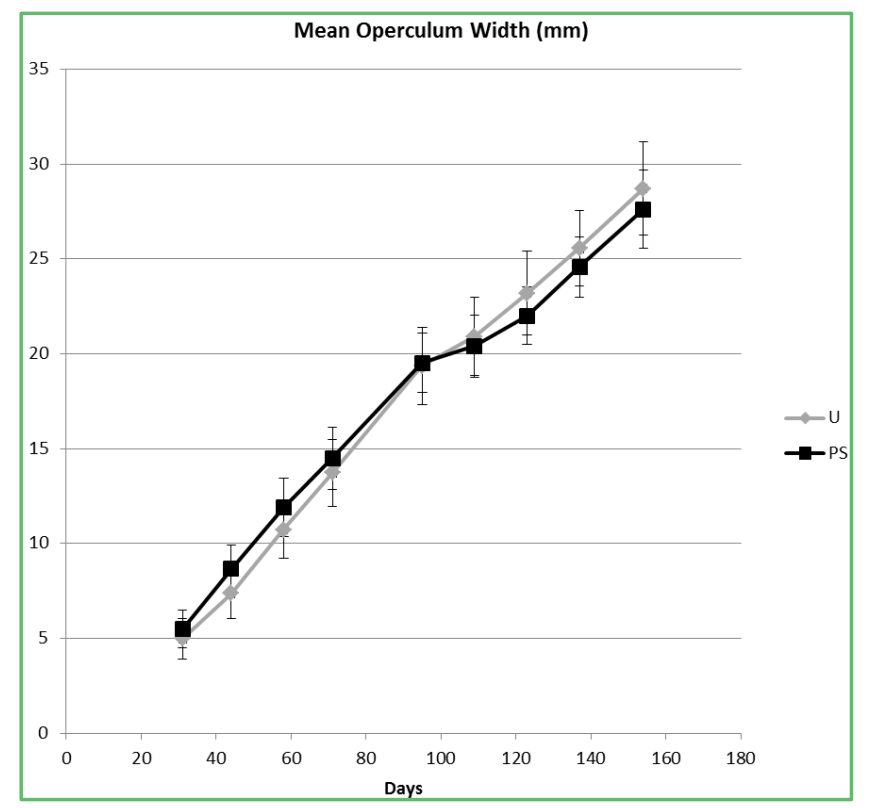

Figure 4. Growth rates in operculum width between snails in the unsubmerged (U) and partially submerged (PS) treatments. Error bars represent standard deviation.

\section{Discussion}

In the United States, the non-native Pomacea maculata poses a considerable threat to agriculture and wetland areas [8]. Water bodies in southern Florida undergo frequent fluctuations in water level, which are controlled by pumps, culverts and gates. These frequent fluctuations in water level cause Pomacea egg clutches on emergent macrophytes to become submerged. Submerged clutches can become detached from the vegetation and float to the surface. These floating clutches can be easily transported through water control structures and management canals, facilitating the invasion of non-impacted areas.

The effects of water stress on various Pomacea $s p$. have shown a reduction in hatching rates in submerged clutches[2,11,12]. The physiological stress provoked by submersion may be related to oxygen availability, solute losses, $\mathrm{pH}$ changes or osmotic pressure [2].Exposure to water stress minimally decreased hatching success of $P$. maculata clutches during this study. The Mann Whitney test detected no significant difference in means between treatments, despite an apparent difference in mean hatching success between treatments. Some clutches were unable to maintain their structural integrity, allowing individual eggs to float on the surface or fall to the bottom. Individual eggs may have a higher survival rate because they are less conspicuous to predators [10].

Barnes [9] estimated a mean of 2064 eggs per clutch for this species. Based on this estimate, approximately $49 \%$ of the unsubmerged eggs in this study hatched, whereas $43 \%$ of partially submerged and $29 \%$ of the floating eggs successfully hatched. Despite this decreased hatching efficiency, the strategy of dislodging the clutch into the water can still potentially result in nearly 600 individuals per clutch, who within a matter of months able to reproduce themselves.

The various control methods implemented for nonnative Pomacea sp. have included molluscicides, pesticides, biological control, mechanical methods, and manual removal. Molluscicides can be expensive, compromise human health, and negatively impact the environment. When pesticides are used a single application will kill only the snails in the water, not the egg clutches above the surface, and a second application is suggested before hatchlings reach reproductive age [13]. Biological control agents such as ducks and fish can reduce numbers, but has the potential to do more harm to the native environment [13]. Wire grills can be placed over gates and culverts preventing larger snails from dispersing. Gastropods are well known not to cross strips of copper; placing copper sheet barriers has been suggested as a means to keep Ampullariidae out of uninfested areas [13]. Manual removal includes the removal of snails and clutches by several methods. Baiting and draining can be used to encourage Pomacea snails to congregate in a localized area making them easier to manually remove.

In general Ampullariidae cannot be eradicated and methods must be developed to reduce their populations and the damage they cause [13]. It is economically cost effective to deal with potential pest species in the early phase of invasion [14]. Currently P. maculata are invading Arthur R. Marshall Loxahatchee National Wildlife Refuge. A control method of baiting for adult and juvenile snails combined with the manual removal, and crushing or freezing of egg clutches could be an effective way to maintain a manageable population of $P$. 
maculata. A more thorough understanding of the biology of $P$. maculata is also necessary if this ongoing invasion is to be brought under control.

\section{Acknowledgements}

This study was funded by a Palm Beach Atlantic University Quality Initiative Research Grant. Donatto Surratt, Rebekah Gibble, Tonya Brinn, Marcie Kapsch, Melani Hafsadi, Yasmin Hernandez, Nashka Desrosiers, Tiffany Trent, and Gary Goss assisted in the completion of this study.

\section{REFERENCES}

[1] Rawlings, T.A., Hayes, K.A., Cowie, R.H. and Collins, T. M.. The identity, distribution, and impacts of non-native apple snails in the continental United States. BMC Evolutionary Biology 7: 97-111,2007.

[2] Pizani, N.V., Estebenet, A.L., and Martin, P.R. Effects of submersion and aerial exposure on clutches and hatchlings of Pomacea canaliculata (Gastropoda: Ampullariidae). American Malacological Bulletin 20: 55-63, 2005.

[3] Aditya, G. and Raut, S.K. Destruction of Indoplanorbis exustus (Planorbidae) eggs by Pomacea bridgesi (Ampullariidae). Molluscan Research 22:87-90, 2002.

[4] Hollingsworth, R. G., Cowie, R. H., Joshi, R. C., AND Sebastian, L. S. Apple snails as disease vectors. Global advances in ecology and management of golden apple snails, 121-132, 2006.

[5] Stevens, A.J., Stevens, N.M., Darby, P.C., and Percival, H.F. Observations of fire ants (Solenopsis invicta Buren) attacking apple snails (Pomacea paludosa Say) exposed during dry down conditions. Molluscan Studies 65: 507-510, 1999.

[6] Seuffert, M. E., and Martín, P. R. Influence of temperature, size and sex on aerial respiration of Pomacea canaliculata (Gastropoda: Ampullariidae) from Southern Pampas, Argentina. Malacologia,51(1), 191-200, 2009.

[7] Carlsson N.O.L, and Bronmarlk C, Hansson L.A. Invading herbivory: the golden apple snail alters ecosystem functioning in Asian wetlands. Ecology 85:1575-1580,2004.

[8] Howells, R.G., Burklova, L.E., Karatayev, A.Y., Marfurt, R.K. and Burks, R.L.Native and introduced Ampullaridae in NorthAmerica: history, status, and ecology. In: Global advances in ecology and management of golden applesnails (R.C. Joshi and L.S. Sebastion, eds), 73-112. Philippine Rice research Institute, Nueva Ecija, 2006.

[9] Barnes, M.R., Fordham, R., Burks, R., and Hand, J.J. Fecundity of the exotic apple snail, Pomacea insularum. Journal of North American Benthological Society 27:738-745,2008.

[10] Youens, A. K., and Burks, R. L. Comparing applesnails with oranges: the need to standardize measuring techniques when studying Pomacea. Aquatic Ecology, 42(4), 679-684, 2008.

[11] Horn, K.C., Johnson, K.M., Moore, A., Siemann, E., and Gabler, C.A. Factors affecting hatching success of golden apple snail eggs: Effects of water immersion and cannibalism. Wetlands 28(2) 544-549, 2008.

[12] Turner, R.L. Effects of submergence on embryonic survival and developmental rate of the Florida applesnail, Pomacea paludosa: Implications for egg predation and marsh management. Florida Scientist 6: 118-129, 1998.

[13] Cowie, R.H. Apple snails (Ampullariidae) as agricultural pests: their biology, impacts and management. Apple snails are agricultural pests: the biology, impacts, and management. In: Mollusks as crop pests (G. M. Barker, ed.), 1-28. CABI, Wallingford, Connecticut, 2002.

[14] Naylor, R. Invasions in agriculture: Assessing the cost of the golden apple snail in Asia.1996. Ambio 25 No7: 443-448, 1996. 